\title{
Prevalence and risk factors for prolonged QT interval and QT dispersion in patients with type 2 diabetes
}

\author{
Vladan M. Ninkovic ${ }^{1}$ Srdjan M. Ninkovic ${ }^{2,3}$ - Vanja Miloradovic ${ }^{2,3}$. \\ Dejan Stanojevic $^{1} \cdot$ Marijana Babic $^{1} \cdot$ Vojislav Giga $^{4} \cdot$ Milan Dobric $^{4} \cdot$ \\ Michael I. Trenell ${ }^{5,6} \cdot$ Nebojsa Lalic $^{4} \cdot$ Petar M. Seferovic $^{4} \cdot$ Djordje G. Jakovljevic $^{5,6,7}$
}

Received: 29 January 2016/ Accepted: 30 March 2016/Published online: 23 April 2016

(c) The Author(s) 2016. This article is published with open access at Springerlink.com

\begin{abstract}
Aims Prolonged QT interval is associated with cardiac arrhythmias and sudden death. The present study determined the prevalence of prolonged QT interval and QT dispersion and defined their clinical and metabolic predictors in patients with type 2 diabetes.

Methods Cross-sectional study included 501 patients with type 2 diabetes. A standard 12-lead electrocardiogram was recorded. QT corrected for heart rate $(\mathrm{QTc})>440 \mathrm{~ms}$ and QT dispersion (QTd) $>80 \mathrm{~ms}$ were considered abnormally prolonged. QTc $\geq 500 \mathrm{~ms}$ was considered a high-risk QTc
\end{abstract}

Managed by Massimo Federici.

Petar M. Seferovic and Djordje G. Jakovljevic are joint senior authors.

Vladan M. Ninkovic

ninkov@sbb.rs

$\bowtie$ Djordje G. Jakovljevic

djordje.jakovljevic@newcastle.ac.uk

1 Department of Cardiology, Specialist Hospital Merkur, Bulevar Srpskih Ratnika 18, 36210 Vrnjacka Banja, Serbia

2 Clinical Centre, Kragujevac, Serbia

3 Medical School, University of Kragujevac, Kragujevac, Serbia

4 Cardiology Department, Clinical Centre of Serbia, Medical School, University of Belgrade, Belgrade, Serbia

5 Institute of Cellular Medicine, Faculty of Medical Sciences, Medical School, Newcastle University, Framlington Place, William Leech B., NE2 4HH Newcastle upon Tyne, UK

6 Research Councils UK Centre for Ageing and Vitality, Newcastle University, Newcastle upon Tyne, UK

7 Clinical Research Facility, Royal Victoria Infirmary, Newcastle upon Tyne, UK prolongation. Demographic, clinical and laboratory data were collected. Independent risk factors for prolonged QTc and QTd were assessed using logistic regression analysis. Results Prevalence of QTc $>440 \mathrm{~ms}$ and QTd $>80 \mathrm{~ms}$ were 44.1 and $3.6 \%$, respectively. Prevalence of high-risk QTc ( $\geq 500 \mathrm{~ms}$ ) was $2 \%$ only. Independent risk factors for QTc prolongation $>440 \mathrm{~ms}$ were mean blood glucose $(\beta=2.192, \quad p<0.001)$, treatment with sulphonylurea $(\beta=5.198, \quad p=0.027), \quad$ female gender $(\beta=8.844$, $p<0.001)$, and coronary heart disease $(\beta=8.636$, $p=0.001)$. Independent risk factors for QTc $\geq 500 \mathrm{~ms}$ were coronary heart disease $(\beta=4.134, p<0.001)$ and mean blood glucose level $(\beta=1.735, p<0.001)$. The independent risk factor for prolonged QTd was only coronary heart disease $(\beta=5.354, p<0.001)$.

Conclusions Although the prevalence of prolonged QTc $>440 \mathrm{~ms}$ is significant, the prevalence of high-risk QTc ( $\geq 500 \mathrm{~ms}$ ) and QTd $>80 \mathrm{~ms}$ is very low in patients with type 2 diabetes. Hyperglycaemia and coronary heart disease are strong predictors of high-risk QTc.

Keywords Type 2 diabetes $\cdot$ ECG $\cdot$ QT interval $\cdot$ QT dispersion

\section{Introduction}

The QT interval in the surface electrocardiogram (ECG) reflects the total duration of depolarization and repolarization of the ventricles. QT dispersion (QTd) represents nonuniformity of regional myocardial ventricular repolarization and is reflected by differences of the QT interval duration between ECG leads. Both prolonged QT interval and prolonged QTd form a substrate for malignant ventricular arrhythmias. Previous studies showed that a 
prolonged QT interval and QT dispersion are predictors of cardiovascular mortality and all-cause mortality in patients after acute myocardial infarction [1], patients with heart failure [2], patients with diabetes type 1 and 2 [3, 4], patients with idiopathic long QT syndrome [5] and in the population of apparently healthy individuals [6, 7].

The aims of this study were to determine the prevalence of prolonged QT interval and QT dispersion in patients with type 2 diabetes and their correlations with clinical and metabolic parameters, with particular emphasis on coronary heart disease, the parameters of glycaemic control and type of diabetes treatment.

\section{Methods}

\section{Study design and patients}

This cross-sectional study included 501 Caucasian patients with type 2 diabetes (277 men) treated at the National Educational Centre and Hospital for Diabetes, "Merkur" Vrnjačka Banja, Serbia, from September 2011 until December 2012. Study was approved by the local research committee and all the procedures were according to Declaration of Helsinki and all study participants provided written informed consent. The mean age (SD) was 60.4 (8.1) years, and the mean duration of diabetes (SD) was 9.9 (6.8) years.

Type 2 diabetes was defined as a diagnosis made after 39 years of life with the lack of need for insulin treatment within the first year after diagnosis. Hypertension was defined as systolic blood pressure $>140 \mathrm{mmHg}$ and/or diastolic blood pressure $>90 \mathrm{mmHg}$ during $\geq 2$ measurements, or current antihypertensive therapy. Retinopathy was assessed by retinal photographs centrally graded by a single observer. Distal symmetric neuropathy was diagnosed according to the EMNG findings, or relevant signs and symptoms including determination of vibratory perception threshold. Coronary heart disease was defined as the history of previous myocardial infarction, unstable angina, coronary artery bypass grafting, percutaneous coronary intervention, positive findings on coronary angiography, positive ECG stress test, typical effort angina, or Minnesota code 1.1 or 1.2 in a surface ECG [8].

Estimated glomerular filtration rate (eGFR) was calculated according to serum creatinine level using the MDRD formula [9].

All patients were free of clinical signs of the existence of cardiovascular autonomic neuropathy (i.e. orthostatic hypotension). The study excluded patients with ECG signs of myocardial hypertrophy, bundle branch block, as well as patients on treatment with drugs known to affect the QT interval, especially antiarrhythmic class I and III, digitalis, and antidepressants.

\section{QT interval length and QT dispersion}

In a standard ECG (Schiller AT1, Cardiovit, Switzerland), recorded in a supine position, RR and QT intervals were measured by two independent observers, who were blinded to patients' data, using a ruler and magnifying glass. QT interval was measured from the beginning of QRS complex to the end of the $\mathrm{T}$ wave in the intersection with the isoelectric line [10]. QT corrected for the length of the previous cycle (QTc) was obtained using Bazett's formulae: $\mathrm{QTc}=\mathrm{QT} / \sqrt{\mathrm{RR}}(\mathrm{sec})[11]$.

QTc is the mean of QTc from five consecutive cycles in lead V5. QTc $>440 \mathrm{~ms}$ was considered abnormally prolonged, whereas QTc $\geq 500 \mathrm{~ms}$ was considered high-risk QT prolongation. RR and QT intervals were also measured in three consecutive cycles in each of the six thoracic lead. QTc dispersion (QTd) was calculated as the difference between the maximum and minimum QTc at any thoracic lead. QTd $>80 \mathrm{~ms}$ was considered an abnormally prolonged [12].

For each patient the values of QTc and QTd represent average values of the readings of the two observers. ECG recordings were performed on the same day as daily glycaemia profile.

\section{Parameters of glycaemic control}

After hospitalization, the patients were put on a dietary regimen. For each patient calorie intake was calculated based on ideal body weight (IBW) and estimates of daily calorie consumption (25-30 kcal/IBW). The composition of the meal was carbohydrates $60 \%$, protein $20 \%$ and fat $20 \%$. Meals were taken at 7:30 AM, 12:00 AM and 6:00 PM. On the second day of admission, glycaemic daily profile was determined for each patient. Glucose levels were determined from capillary blood sample using the glucose hexokinase assay (EKF Diagnostics, Germany). In patients treated with oral hypoglycaemic agents, daily profile consists of six capillary blood glucose values: three before each main meal (at 7:30 AM, 12:00 AM, and 6:00 PM) and three $2 \mathrm{~h}$ after the main meal (at 10:00 AM, 2:30 $\mathrm{PM}$ and 8:30 PM). In patients who received insulin, daily glycaemia profile included two additional blood samples taken at 12:00 midnight and 3:00 AM, giving a total of 8 values. From the analysis were excluded patients with hypoglycaemic values in daily glycaemia profile, due to potential influence of reflex sympathetic stimulation on the length of the QT interval. Hypoglycaemia was defined as glucose levels $<3.9 \mathrm{mmol} / \mathrm{L}$ (70 $\mathrm{mg} / \mathrm{dL})$. 
The following parameters of glycaemic control were used: fasting blood glucose (FBG), the mean postprandial glucose, the mean blood glucose (MBG), the mean amplitude of glycaemic excursion (MAGE) and glycated haemoglobin A1c (HbA1c). To assess glycaemic fluctuations during the day, we used the MAGE, described by the Service et al. [13]. It is calculated as the arithmetic mean of the absolute differences of the peak and subsequent nadir of blood glucose values in daily glycaemia profile, wherein in calculation are taken only differences $>1$ SD of the mean glycaemia value. The MAGE is an independent measure of mean blood glucose value designed to evaluate daily fluctuations in blood glucose. A significant relationship was previously demonstrated between such model of discontinuous glucose sampling and model of continuous subcutaneous glucose monitoring [14]. All laboratory data were centrally collected and patients' screening was performed during hospitalization period with the same instrument and observer.

\section{Statistical analysis}

All statistical analysis was carried out using SPSS version 21.0 (SPSS Inc. Chicago, IL). Prior to statistical analysis, data were checked for univariate and multivariate outliers using standard Z-distribution cut-offs and Mahalanobis distance tests. Normality of distribution was assessed using a KolmogorovSmirnov test. Differences in clinical characteristics of patients between subgroups of QTc ( $\leq 440$ or $>440$ ms duration) and QTc dispersion ( $\leq 80$ or $>80 \mathrm{~ms}$ ) were assessed using the $t$ test for continuous variables as appropriate; results are shown as mean \pm standard deviation (SD). Differences between categorical variables were assessed using Chi-squared test. To assess variables that were independently predictive of prolonged QTc duration and QTc dispersion, we used logistic regression analysis. Variables entered into initial model were age, sex, diabetes duration, body mass index, systolic and diastolic blood pressure, coronary heart disease, stroke, retinopathy, polyneuropathy, diabetes therapy (metformin, sulphonylurea, insulin), fasting glucose, mean postprandial glucose, mean blood glucose, MAGE, HbA1c, total cholesterol, triglycerides, and estimated glomerular filtration rate. Variables were retained in the final model if they added significantly to the likelihood of models or to the estimated coefficients of predictors. Statistical significance was indicated if $p<0.05$.

\section{Results}

Patients' demographic, clinical and metabolic data are presented in Table 1. Prevalence of prolonged QTc duration and QTc dispersion in patients with type 2 diabetes
Table 1 Patients demographic, clinical and metabolic characteristics

\begin{tabular}{|c|c|}
\hline Total number of patients & 501 \\
\hline Gender (male/female) & $277 / 224$ \\
\hline Age (years) & $60.4 \pm 8.1$ \\
\hline Diabetes duration (years) & $9.9 \pm 6.9$ \\
\hline Body mass index $\left(\mathrm{kg} / \mathrm{m}^{2}\right)$ & $30.4 \pm 4.8$ \\
\hline Systolic blood pressure (mmHg) & $136.7 \pm 48.7$ \\
\hline Diastolic blood pressure $(\mathrm{mmHg})$ & $80.8 \pm 7.0$ \\
\hline Coronary heart disease $(\%)$ & 22.9 \\
\hline Stroke $(\%)$ & 6.8 \\
\hline Retinopathy (\%) & 47.5 \\
\hline Polyneuropathy (\%) & 74.5 \\
\hline Metformin (\%) & 77.2 \\
\hline Sulphonylurea (\%) & 38.5 \\
\hline Insulin $(\%)$ & 69.1 \\
\hline Fasting glucose (mmol/l) & $8.9 \pm 2.9$ \\
\hline Mean postprandial glucose $(\mathrm{mmol} / \mathrm{l})$ & $10.4 \pm 3.5$ \\
\hline Mean blood glucose $(\mathrm{mmol} / \mathrm{l})$ & $9.3 \pm 3.0$ \\
\hline MAGE (mmol/l) & $4.1 \pm 2.1$ \\
\hline HbA1c $(\%)$ & $8.1 \pm 1.4$ \\
\hline Total cholesterol $(\mathrm{mmol} / \mathrm{l})$ & $5.8 \pm 1.5$ \\
\hline Triglycerides (mmol/l) & $2.1 \pm 1.6$ \\
\hline eGFR $\left(\mathrm{ml} / \mathrm{min} / 1.73 \mathrm{~m}^{2}\right)$ & $96.4 \pm 22.7$ \\
\hline
\end{tabular}

MAGE mean amplitude of glycaemic excursion, $e G F R$ estimated glomerular filtration rate

were 44.1 and $3.6 \%$. Additionally, $2 \%$ of patients demonstrated prolonged QTc interval of $\geq 500 \mathrm{~ms}$. QTc duration and dispersion were affected by the gender with females demonstrating significantly higher prevalence of prolonged QTc duration (both $>440$ and $>500 \mathrm{~ms}$ ) than men (55 vs $36 \%$, and 4 vs $1 \%, p<0.05)$ and QTc dispersion ( 5 vs $3 \%, p<0.05$; Table 2$)$.

Patients with prolonged QTc interval had significantly higher age $(p<0.02)$, body mass index $(p<0.01)$, and prevalence of coronary heart disease $(p<0.01)$, retinopathy $(p<0.01)$, polyneuropathy $(p<0.01)$, and the use of sulphonylurea $(p<0.01$; Table 3$)$. Measures of metabolic control, i.e. HbA1c, daily glucose fluctuation (MAGE), mean blood glucose, fasting blood glucose, mean postprandial glucose and triglycerides, were significantly higher in patients with QTc interval duration of $>440 \mathrm{~ms}$ $(p<0.05$; Table 3). Patients with prolonged QTd showed significantly higher age and prevalence of coronary artery disease.

There was a significant moderate relationship between the QTc duration and QTc dispersion $(r=0.36$, $p<0.001)$. However, $50 \%$ of patients with a normal QT interval dispersion $(<80 \mathrm{~ms})$ showed an increased QTc interval duration $(>440 \mathrm{~ms})$. 
Table 2 Prevalence of increased QTc interval duration and QTc dispersion in patients with type 2 diabetes

\begin{tabular}{lccc}
\hline & Males $(n=277)$ & Females $(n=224)$ & Total $(n=501)$ \\
\hline Increased QTc duration $(>440 \mathrm{~ms})$ & $35.7(28.2-39.1)$ & $54.5(46.0-61.2)^{*}$ & $44.1(39.6-52.4)$ \\
Increased QTc duration $(\geq 500 \mathrm{~ms})$ & $0.7(0.4-1.1)$ & $3.5(2.7-4.6)^{*}$ & $2.0(1.6-2.4)$ \\
Increased QTc dispersion $(>80 \mathrm{~ms})$ & $2.9(2.3-3.3)$ & $4.5(3.7-5.1)^{*}$ & $3.6(3.0-4.1)$ \\
\hline
\end{tabular}

Values are given as \% $(95 \% \mathrm{CI})$

QTC QT interval corrected for heart rate, $C I$ confidence interval

* Significantly higher than Males $(p<0.05)$

Table 3 Demographic, clinical and metabolic characteristics of patients with type 2 diabetes by QTc duration and QTc dispersion

\begin{tabular}{|c|c|c|c|c|c|c|}
\hline & \multicolumn{3}{|l|}{ QTc duration } & \multicolumn{3}{|l|}{ QTc dispersion } \\
\hline & $\begin{array}{l}<440 \mathrm{~ms} \\
(n=280)\end{array}$ & $\begin{array}{l}>440 \mathrm{~ms} \\
(n=221)\end{array}$ & $p$ & $\begin{array}{l}<80 \mathrm{~ms} \\
(n=483)\end{array}$ & $\begin{array}{l}>80 \mathrm{~ms} \\
(n=18)\end{array}$ & $p$ \\
\hline Age (years) & $59.6 \pm 8.0$ & $61.4 \pm 8.1$ & 0.017 & $60.2 \pm 8.1$ & $64.8 \pm 7.7$ & $\mathbf{0 . 0 2 3}$ \\
\hline Diabetes duration (years) & $9.5 \pm 6.8$ & $10.3 \pm 6.7$ & 0.205 & $9.8 \pm 6.5$ & $11.5 \pm 6.4$ & 0.298 \\
\hline Body mass index $\left(\mathrm{kg} / \mathrm{m}^{2}\right)$ & $29.9 \pm 4.5$ & $31.1 \pm 5.2$ & 0.005 & $30.4 \pm 4.9$ & $30.3 \pm 3.7$ & 0.921 \\
\hline Systolic blood pressure (mmHg) & $135.9 \pm 63.2$ & $137.6 \pm 17.3$ & 0.665 & $136.8 \pm 49.5$ & $133.6 \pm 17.1$ & 0.497 \\
\hline Diastolic blood pressure $(\mathrm{mmHg})$ & $80.4 \pm 6.5$ & $81.4 \pm 7.6$ & 0.140 & $80.9 \pm 7.0$ & $79.4 \pm 6.6$ & 0.379 \\
\hline Coronary heart disease $(\%)$ & 15.4 & 33.1 & $<0.001$ & 21.3 & 66.7 & 0.001 \\
\hline Stroke $(\%)$ & 5.1 & 7.7 & 0.520 & 5.6 & 5.3 & 0.969 \\
\hline Retinopathy (\%) & 35.4 & 57.6 & 0.002 & 32.5 & 38.4 & 0.815 \\
\hline Polyneuropathy (\%) & 68.6 & 80.1 & 0.005 & 72.7 & 77.5 & 0.699 \\
\hline Metformin $(\%)$ & 77.5 & 76.9 & 0.879 & 77.2 & 77.9 & 0.985 \\
\hline Sulphonylurea (\%) & 33.2 & 45.2 & 0.006 & 38.3 & 44.9 & 0.622 \\
\hline Insulin $(\%)$ & 71.1 & 66.5 & 0.277 & 68.9 & 72.4 & 0.770 \\
\hline Fasting glucose $(\mathrm{mmol} / \mathrm{l})$ & $8.3 \pm 2.3$ & $9.6 \pm 3.3$ & $<0.001$ & $8.9 \pm 2.9$ & $8.3 \pm 2.1$ & 0.305 \\
\hline Mean postprandial glucose $(\mathrm{mmol} / \mathrm{l})$ & $9.5 \pm 2.7$ & $11.5 \pm 4.1$ & $<0.001$ & $10.4 \pm 3.5$ & $10.5 \pm 2.9$ & 0.814 \\
\hline Mean blood glucose (mmol/l) & $8.5 \pm 2.2$ & $10.3 \pm 3.6$ & $<0.001$ & $9.2 \pm 3.1$ & $9.5 \pm 2.7$ & 0.741 \\
\hline MAGE (mmol/l) & $3.8 \pm 1.8$ & $4.4 \pm 2.3$ & 0.004 & $4.1 \pm 2.0$ & $4.9 \pm 2.8$ & 0.267 \\
\hline HbA1c $(\%)$ & $7.9 \pm 1.3$ & $8.3 \pm 1.4$ & 0.001 & $8.1 \pm 1.4$ & $8.0 \pm 1.0$ & 0.822 \\
\hline Total cholesterol (mmol/l) & $5.6 \pm 1.6$ & $5.7 \pm 1.4$ & 0.706 & $5.7 \pm 1.5$ & $4.9 \pm 1.1$ & 0.380 \\
\hline Triglycerides (mmol/l) & $2.0 \pm 1.0$ & $2.3 \pm 2.1$ & 0.022 & $2.1 \pm 1.6$ & $2.0 \pm 0.7$ & 0.605 \\
\hline eGFR (ml/min/1.73 m²) & $94.9 \pm 24.6$ & $98.2 \pm 30.9$ & 0.461 & $97.1 \pm 20.0$ & $75.7 \pm 44.5$ & 0.346 \\
\hline
\end{tabular}

$p<0.05$ denotes statistical significance

$M A G E$ mean amplitude of glycaemic excursion, $e G F R$ estimated glomerular filtration rate

In multivariate logistic regression analyses and after adjustment for age and gender, the independent predictors of prolonged QTc interval were mean blood glucose $(\beta=2.192$, $p<0.001)$, female gender $(\beta=8.844, p<0.001)$, coronary artery disease $(\beta=8.636, p=0.001)$, and treatment with sulphonylurea $(\beta=5.198, p=0.027$; Table 4$)$. On the other note, only coronary heart disease was independent predictor a prolonged QTc dispersion $(\beta=5.354, p<0.001)$, adjusted for age and gender. Finally, the independent predictors of increased QTc duration of $\geq 500 \mathrm{~ms}$ were coronary heart disease $(\beta=4.134, p<0.001)$ and mean blood glucose level $(\beta=1.735, p<0.001)$.

\section{Discussion}

In our population of patients with type 2 diabetes, the prevalence of QTc $>440 \mathrm{~ms}$ is relatively high and accounts to $44.1 \%$. However, the prevalence of high-risk QTc $\geq 500 \mathrm{~ms}$ is only $2 \%$. It has been shown in patients with congenital and acquired long QT syndrome that malignant arrhythmias are most often associated with values of $500 \mathrm{~ms}$ or more [15-18]. Our data show that the largest proportion of patients with prolonged QTc is in the "grey zone" between arbitrarily taken value of 440 and $500 \mathrm{~ms}$, and that the percentage of patients with a real risk 
Table 4 Predictors of prolonged QTc interval and QTc dispersion in patients with type 2 diabetes

\begin{tabular}{llr}
\hline & $\beta$ & \multicolumn{1}{c}{$p$} \\
\hline QTc duration $>440 \mathrm{~ms}$ & & \\
Mean blood glucose & 2.192 & $<0.001$ \\
Coronary artery disease & 8.636 & $<0.001$ \\
Treatment with sulphonylurea & 5.198 & 0.027 \\
Female gender & 8.844 & $<0.001$ \\
QTc duration $>550 \mathrm{~ms}$ & & \\
Mean blood glucose & 1.736 & $<0.001$ \\
Coronary artery disease & 4.134 & $<0.001$ \\
QTc dispersion & & \\
Coronary artery disease & 5.354 & $<0.001$ \\
\hline
\end{tabular}

of malignant arrhythmias is low (2\%). The prevalence of pathological QTd (>80 ms) is also low $(3.6 \%)$.

These findings are important as they demonstrate that the prevalence of highly prolonged QTc and QTd, which can be associated with severe arrhythmias, is low in patients with type 2 diabetes. From our clinical practice we know that sudden death due to life-threatening arrhythmias in patients with type 2 diabetes is not very common. Sudden death is rather caused by acute cardiovascular events, i.e. myocardial infarction and stroke. Coronary artery disease and poor metabolic control are often the triggers of high-risk QTc and sudden death.

Previous studies in patients with type 2 diabetes showed that the prevalence of QTc and QTd is markedly different and ranged from 15.4 to $67 \%$ for QTc, and from none to $33 \%$ for QTd [19-22]. Such large differences may result from inaccurate identification of the beginning and the end of the QT interval by the observer or the software in the case of automatic analysis of ECG tracings, or the result of selection bias. Furthermore, QTd differences are consequence of different cut-off values in the definition of pathological QTd (between 50 and $80 \mathrm{~ms}$ ).

There are several risk factors connected with repolarization disturbances in previous studies. Earlier studies have suggested a relationship between diabetic cardiovascular autonomic neuropathy (CAN) and QT prolongation. Since the determination of CAN using classical cardiovascular tests is complicated [23], it has been proposed that determination of QTc duration is specific and easier methods for detection of CAN [24]. However, later studies have not confirmed association of prolonged QT and CAN in diabetes type 1 and $2[25,26]$. Moreover, a large metaanalysis that investigated the sensitivity and specificity of prolonged QT interval for the detection of CAN in patients with diabetes suggested that prolonged QT interval is a poor indicator of CAN [27]. Previous studies have also not demonstrated significant relationship between QTd and autonomic dysfunction in diabetic patients [28].

Several other risk factors were indicated in prolonged QT interval in diabetes, including systolic and diastolic blood pressure [22, 29, 30], hyperglycaemia [22, 31], serum insulin level $[29,32]$, microvascular diabetic complication [22, 33] and coronary heart disease [20, 29]. As risk factors for prolonged QTd in the literature are also reported CAN [34], arterial hypertension [28], and coronary heart disease [20, 35]. It has become clear that independent risk factors for QTc and QTd prolongation in patients with type 2 diabetes are different and depend primarily on the set of variables tested.

Independent risk factors for QTc $>440 \mathrm{~ms}$ in patients with type 2 diabetes in our study group were: hyperglycaemia, the use of sulphonylurea agents in the treatment of diabetes, female gender and coronary heart disease. Independent risk factors for QTc $\geq 500 \mathrm{~ms}$ were only hyperglycaemia and coronary heart disease. Independent risk factor for QTd $>80 \mathrm{~ms}$ was coronary heart disease.

It was previously suggested that hyperglycaemia may lead to QT prolongation through several mechanisms including stimulation of protein kinase $\mathrm{C}$ leading to reduced synthesis and release of endothelial derived nitric oxide [36, 37]. This consequently lead to decrease in activity of $\mathrm{Na}+\mathrm{K}+$ ATPase, an enzyme responsible for the maintenance of basal membrane potential of myocytes, and cells of the conduction system (by maintaining a high concentration of intracellular $\mathrm{K}$ and high concentration of extracellular $\mathrm{Na}$ by mechanism of active transport) [36, 37]. Reduced nitric oxide bioavailability during hyperglycaemia is probably responsible for decreased activity of $\mathrm{Ca}^{2+}$ ATPase as well, an enzyme in the membrane of myocytes that through active transport mechanism maintains a low concentration of $\mathrm{Ca}^{2+}$ ions in the cell, resulting in an increase in the influx of $\mathrm{Ca}^{2+}$ ions during phase 2 of the action potential and extension of QT interval [38].

Correlation between hyperglycaemia and QT interval has been demonstrated in previous clinical studies including patients with impaired glucose metabolism and in apparently healthy individuals [22, 31, 39, 40]. Moreover, in both clinical studies and experimental models, it has been suggested that acute hyperglycaemia leads to prolonged QT interval not only in healthy subjects but also in those with diabetes [41, 42].

Our results are in agreement with these suggestions, given that the mean blood glucose derived from daily glycaemia profile is independent risk factor for prolonged QT interval, with a note that the daily profile of glycaemia was determined the same day as the ECG recordings. On the other hand, the relationship between glycaemia and QTd has not been previously reported [28]. 
The effect of sulfonylurea agents on the incidence of cardiovascular events in patients with diabetes is still controversial. The closure of KATP channels in myocytes under the influence of sulfonylurea leads to the depolarization of the plasma cell membrane, opening of voltagedependent $\mathrm{Ca}^{2+}$ channels with an increase in the influx of $\mathrm{Ca}^{2+}$ ions into the cell which generates a prolongation of action potential during phase 2 of the action potential or plateau phase. This results in a prolongation of the QT interval in the ECG. The data in the literature on the relationship between the treatment of diabetes with sulfonylureas and QT prolongation are scarce. In a small group of subjects, Najeed and collaborators have found a significant increase in QTc interval (and QT dispersion) after 2 months of treatment with glibenclamide (from $433 \pm 24$ to $467 \pm 24 \mathrm{~ms}$ ), as opposed to patients receiving treatment with metformin [43].

Influence of female gender on QT prolongation is well established [33]. Normal adult women have longer QT intervals than men, so widely accepted cut-off value for the normal QTc interval is $440 \mathrm{~ms}$ for men and $460 \mathrm{~ms}$ for women [44]. Moreover, as to heart rate dependence of the QT interval, adult women have longer QT intervals at longer cycle lengths than men [45]. However, electrophysiological substrate for such gender differences is largely unknown.

During ischaemia, sympathetic hyperactivity accompanied by an underlying myocardial structural damage is likely to increase the ventricular repolarization duration measured as QT interval on the body surface electrocardiogram. There is strong evidence suggesting the association between QT abnormalities and acute and chronic cardiac ischaemia [46, 47]. Moreover, QT prolongation and QTd can be reduced by successful revascularization [48].

The underlying mechanism during acute ischaemia responsible for the heterogeneity of repolarization $(\mathrm{QTd})$ could be identified on a cellular level as a decrease of the resting membrane potential in the course of acute ischaemia, leading to a cellular uncoupling and a shortening of the action potential duration [49].

In chronic ischaemic heart disease, QTd seems to represent the sum of several adverse cardiac abnormalities such as fibrosis, hypertrophy, dilatation, ischaemia and probably, autonomic dysfunction [50]. Obviously, QTd could be considered as a non-invasive marker of potentially lethal underlying cardiac abnormalities-the most important being ischaemia. Our results are in accordance with the findings of these studies and studies that have investigated the association between cardiac ischaemia and repolarization disturbances in patients with type 2 diabetes [20, 29, 35].

\section{Study limitations}

The present study is not without limitations. The lack of longitudinal data and follow-up patients' clinical course prevents generalization of the data and identification of predictors associated with increased morbidity and mortality in patients with type 2 diabetes, and in particular development of potential life-threatening arrhythmias in those with prolonged QTc interval. Only Caucasian patients were included and prevalence and risk factors for prolonged QTc interval and QT dispersion in patients with other ethnic origins remains to be defined.

\section{Conclusion}

The prevalence of QT prolongation $>440 \mathrm{~ms}$ is relatively high $(44.1 \%)$, but the prevalence of high-risk QT prolongation $(\geq 500 \mathrm{~ms}$ ), and QT dispersion $>80 \mathrm{~ms}$ in patients with type 2 diabetes is low ( 2 and $3.6 \%$ respectively). The use of sulfonylurea agents in the treatment of diabetes and female gender are reasons for clinically irrelevant QT prolongation in patients with type 2 diabetes. Risk factors for high-risk prolonged QT interval ( $\geq 500 \mathrm{~ms}$ ) are acute hyperglycaemia and history of coronary heart disease. The independent risk factor for prolonged QT dispersion in type 2 diabetes is coronary heart disease.

Acknowledgments We would like to thank Dr Guy MacGowan, Consultant Cardiologist, Freeman Hospital, Newcastle upon Tyne, for critical review of the manuscript.

Authors contribution VMN and DGJ designed the study, performed statistical analysis, and drafted the manuscript. DS and MB assisted in data collection. VG, MD, and PMS conceived of the study, participated in its design, and assisted in statistical analysis. SMN, VM, MIT, and NL assisted in data interpretation and critically reviewed the manuscript. All authors read and approved the final manuscript.

\section{Compliance with ethical standards}

Conflict of interest The authors declare that they have no conflicts of interest.

Ethical standard The study was approved by the local Institutional Review Board.

Human and animal rights All procedures followed were in accordance with the ethical standards of the responsible committee on human experimentation (institutional and national) and with the Helsinki Declaration of 1975, as revised in 2008.

Informed consent Informed consent was obtained from all patients for being included in the study. 
Open Access This article is distributed under the terms of the Creative Commons Attribution 4.0 International License (http://crea tivecommons.org/licenses/by/4.0/), which permits unrestricted use, distribution, and reproduction in any medium, provided you give appropriate credit to the original author(s) and the source, provide a link to the Creative Commons license, and indicate if changes were made.

\section{References}

1. Schwartz PJ, Wolf S (1978) QT interval prolongation as predictor of sudden death in patients with myocardial infarction. Circulation 57:1074-1077

2. Barr CS, Naas A, Freeman M, Lang CC, Struthers AD (1994) QT dispersion and sudden unexpected death in chronic heart failure. Lancet 343:327-329

3. Veglio M, Sivieri R, Chinaglia A, Scaglioni L, Cavallo-Perin P (2000) QT interval prolongation and mortality in type 1 diabetic patients. Diabetes Care 23:1381-1383

4. Naas AA, Davidson NC, Thompson C et al (1998) QT and QTc dispersion are accurate predictors of cardiac death in newly diagnosed non-insulin dependent diabetes: cohort study. BMJ 316(7133):745-746

5. Schwartz PJ, Stramba-Badiale M, Segantini A et al (1998) Prolongation of the QT interval and the sudden infant death syndrome. N Engl J Med 338:1709-1714

6. Schouten EG, Dekker JM, Meppelink P, Kok FJ, Vandenbroucke JP, Pool J (1991) QT interval prolongation predicts cardiovascular mortality in an apparent healthy population. Circulation 84:1516-1523

7. Elming H, Holm E, Jun L et al (1998) The prognostic value of the QT interval and QT interval dispersion in all-cause and cardiac mortality and morbidity in a population of Danish citizens. Eur Heart J 19:1391-1400

8. Prineas RT, Crow RS, Blackburn H (1982) The minnesota code manual of electrocardiographic findings. Laboratory of Physiological Hygiene, School of Public Health, University of Minnesota, Minneapolis

9. Levey AS, Bosch JP, Lewis JB, Greene T, Rogers N, Roth D (1999) A more accurate method to estimate glomerular filtration rate from serum creatinine: a new prediction equation. Modification of Diet in Renal Disease Study Group. Ann Intern Med 130:461-470

10. Ward DE (1988) Prolongation of the QT interval as an indicator of risk of a cardiac event. Eur Heart J 7:139-144

11. Bazett HC (1920) An analysis of time-relations of electrocardiograms. Hearts. 7:353-370

12. Priori SG, Napolitano C, Diehl L, Schwartz PJ (1994) Dispersion of QT interval. A marker of therapeutic efficacy in the idiopathic long QT syndrome. Circulation 89:1681-1689

13. Service FJ, Molnar GD, Rosevear JW, Mackerman E, Gatewood LC, Taylor WF (1970) Mean amplitude of glycemic excursions, a measure of diabetic instability. Diabetes 19:644-655

14. Monnier L, Lapinski H, Colette C (2003) Contributions of fasting and postprandial plasma glucose increments to the overall diurnal hyperglycemia of type 2 diabetic patients. Variations with increasing levels of HbA1c. Diabet Care 26:3881-3885

15. Moss AJ, Schwartz PJ, Crampton RS et al (1991) The long QT syndrome. Prospective longitudinal study of 328 families. Circulation 84:1136-1144

16. Priori SG, Schwartz PJ, Napolitano C et al (2003) Risk stratification in the long-QT syndrome. N Engl J Med 348:1866-1874

17. Yap YG, Camm AJ (2003) Drug induced QT prolongation and torsades de pointes. Heart 89:1363-1372
18. Goldenberg I, Mathew J, Moss AJ et al (2006) Corrected QT variability in serial electrocardiograms in long QT syndrome: the importance of the maximum corrected QT for risk stratification. J Am Coll Cardiol 48:1047-1052

19. Christensen PK, Gall MA, Major-Pedersen A et al (2000) QTc interval length and QT dispersion as predictors of mortality in patients with non-insulin-dependent diabetes. Scand J Clin Lab Invest 60:323-332

20. Veglio M, Bruno G, Borra M et al (2002) Prevalence of increased QT interval duration and dispersion in type 2 diabetic patients and its relationship with coronary heart disease: a populationbased cohort. J Intern Med 251:317-324

21. Kumar R, Fisher M, Whitaker R, Macfarlane PW (2004) Effect of controlling hyperglycemia with diet on QT abnormalities in newly diagnosed patients with type 2 diabetes. Diabet Care 27:2767-2768

22. Li X, Ren H, Zhang-rong X, Liu Y-j, Yang X-p, Liu J-q (2012) Prevalence and risk factors of prolonged QTc interval among Chinese patients with type 2 diabetes. Exp Diabet Res 2012:234084. doi:10.1155/2012/234084

23. Ewing DJ, Martyn CN, Young RJ, Clarke BF (1985) The value of cardiovascular autonomic function tests: 10 years experience in diabetes. Diabet Care 8:491-498

24. Asbury AK, Genuth SM, Griffin J et al (1988) Report and Recommendations of the San Antonio Conference on Diabetic Neuropathy: American Diabetes Association and American Academy of Neurology (Consensus Statement). Diabet Care 11:592-597

25. Bravenboer B, Hendriksen PH, Oey LP, Gispen WH, van Huffelen AC, Erkelens DW (1993) Is the corrected QT interval a reliable indicator of the severity of diabetic autonomic neuropathy? Diabet Care 16(9):1249-1253

26. Valensi PE, Johnson NB, Maison-Blanche P, Extramania F, Motte G, Coumel P (2002) Influence of cardiac autonomic neuropathy on heart rate dependence of ventricular repolarization in diabetic patients. Diabet Care 25(5):918-923

27. Whitsel EA, Boyko EJ, Siscovick DS (2000) Reassessing the role of QTc in the diagnosis of autonomic failure among patients with diabetes: a meta-analysis. Diabet Care 23(2):241-247

28. Cardoso C, Salles G, Bloch K, Deccache W, Siqueira-Filho AG (2001) Clinical determinants of increased QT dispersion in patients with diabetes mellitus. Int J Cardiol 79(2-3):253-262

29. Festa A, D'Agostino R, Rautaharju P, Mykkänen L, Haffner SM (2000) Relation of systemic blood pressure, left ventricular mass, insulin sensitivity, and coronary artery disease to QT interval duration in nondiabetic and type 2 diabetic subjects. Am J Cardiol 86(10): 1117-1122

30. Takebayashi K, Aso Y, Sugita R, Takemura Y, Inukai T (2002) Clinical usefulness of corrected QT intervals in diabetic autonomic neuropathy in patients with type 2 diabetes. Diabet Metab 28(2):127-132

31. Fiorentini A, Perciaccante R, Valente R, Paris A, Serra P, Tubani L (2010) The correlation among QTc interval, hyperglycaemia and the impaired autonomic activity. Auton Neurosci 154(1-2):94-98

32. Kazumi T, Kawaguchi A, Katoh JI, Ikeda Y, Kishi K, Yoshino G (1999) Fasting serum insulin concentrations are associated with QTc duration independent of serum leptin, percent body fat, and BMI. Diabet Care 22(11):1917-1918

33. Subbalakshmi NK, Adhikari PM, Sathyanarayana Rao KN, Jeganathan PS (2010) Influencing factors of QTc among the clinical characteristics in type 2 diabetes mellitus. Diabet Res Clin Pract 88(3):265-272

34. Takebayashi K, Sugita R, Tayama K, Aso Y, Takemura Y, Inukai $\mathrm{T}$ (2003) The connection between QT dispersion and autonomic neuropathy in patients with type 2 diabetes. Exp Clin Endocrinol Diabetes 111(6):351-357 
35. Sakabe K, Fukuda N, Fukuda Y et al (2008) QT-interval dispersion in type 2 diabetic and non-diabetic patients with postmyocardial infarction. Nutr Metab Cardiovasc Dis 18(2):121-126

36. Tesfamariam B, Brown ML, Cohen RA (1991) Elevated glucose impairs endothelium-dependent relaxation by activating protein kinase C. J Clin Invest. 87:1647-1648

37. Gupta S, Sussman I, McArthur CS, Tomheim K, Cohen RA, Ruderman NB (1992) Endothelium-dependent Inhibition of $\mathrm{Na}^{+}$$\mathrm{K}^{+}$ATPase activity in rabbit aorta by hyperglicemia. Possible role of endothelium-derived nitric oxide. $\mathrm{J}$ Clin Invest. 90:727-732

38. Davis FB, Davis PJ, Nat G et al (1985) The effect of in vivo glucose administration on human erythrocyte $\mathrm{Ca} 2+-$ ATPase activity and on enzyme responsiveness in vitro to thyroid hormone and calmodulin. Diabetes 34(7):639-646

39. Lefrandt JD, Diercks GF, van Boven AJ, Crijns HJ, van Gilst WH, Gans RO (2000) High fasting glucose and QTc duration in a large healthy cohort. Diabetologia 43(10):1332-1334

40. Brown DW, Giles WH, Greenlund KJ, Valdez R, Croft JB (2001) Impaired fasting glucose, diabetes mellitus, and cardiovascular disease risk factors are associated with prolonged QTc duration. Results from the Third National Health and Nutrition Examination Survey. J Cardiovasc Risk 8:227-233

41. Marfella R, Nappo F, De Angelis L, Siniscalchi M, Rossi F, Giugliano D (2000) The effect of acute hyperglycaemia on QTc duration in healthy man. Diabetologia 43(5):571-575

42. Gordin D, Forsblom C, Rönnback M, Groop PH (2008) Acute hyperglycaemia disturbs cardiac repolarization in Type 1 diabetes. Diabet Med 25(1):101-105

43. Najeed SA, Khan IA, Molnar J, Somberg JC (2002) Differential effect of glyburide (glibenclamide) and metformin on QT dispersion: a potential adenosine triphosphate sensitive $\mathrm{K}+$ channel effect. Am J Cardiol 90(10):1103-1106

44. Merri M, Benhorin J, Alberti M, Locati E, Moss AJ (1989) Electrocardiographic quantitation of ventricular repolarization. Circulation 80(5):1301-1308

45. Stramba-Badiale M, Locati EH, Martinelli A, Courville J, Schwartz PJ (1997) Gender and the relationship between ventricular repolarization and cardiac cycle length during 24-h Holter recordings. Eur Heart J 18(6):1000-1006

46. Peters RW, Byington RP, Barker A, Yusuf S (1990) BHAT, Study Group11a. Prognostic value of prolonged ventricular repolarization following myocardial infarction: the BHAT experience. J Clin Epidemiol 43(2):167-172

47. Dekker JM, Crow RS, Hannan PJ, Schouten EG, Folsom AR (2004) Heart rate-corrected QT interval prolongation predicts risk of coronary heart disease in black and white middle-aged men and women: the ARIC study. J Am Coll Cardiol 43(4):565-571

48. Mirbolouk F, Arami S, Salari A, Shad B, Kazemnejad E, Moladoust H (2014) Corrected QT-interval and dispersion after revascularization by percutaneous coronary intervention and coronary artery bypass graft surgery in chronic ischemia. J Invasive Cardiol 26(9):444-450

49. Yan GX, Yamada KA, Kleber AG, McHowat J, Corr PB (1993) Dissociation between cellular $\mathrm{K}+$ loss, reduction in repolarization time, and tissue ATP levels during myocardial hypoxia and ischemia. Circ Res 72:560-570

50. Rana BS, Band MM, Ogston S, Morris AD, Pringle SD, Struthers AD (2002) Relation of QT interval dispersion to the number of different cardiac abnormalities in diabetes mellitus. Am J Cardiol 90:483-487 